\title{
STATUS GIZI BADUTA DAN GRAFIK PERTUMBUHAN ANAK USIA 0-23 BULAN DI WILAYAH KERJA PUSKESMAS PANTOLOAN
}

\section{Nutrition Status of Children Under Two Years of Age and Growth Graph of Children Age 0-23 Months in the Working Area Pantoloan Central of Health Community}

\author{
Dwi Erma Kusumawati ${ }^{1 *}$, Latipa ${ }^{1}$, Fahmi Hafid ${ }^{1,2}$ \\ ${ }^{1}$ Poltekkes Kemenkes Palu \\ ${ }^{2}$ Pusat Studi Stunting, STBM dan Kesehatan Kebencanaan Poltekkes Kemenkes Palu \\ *Email korespondensi: dwiekw@ gmail.com
}

\begin{abstract}
ABSTRAK
Anak usia di bawah dua tahun (Baduta) sehat jika mereka tumbuh dan berkembang secara memadai. Pertumbuhan anak baduta adalah proses yang dinamis dimana dibutuhkan kurva pertumbuhan sebagai alat pembanding untuk mengetahui pertumbuhannya sesuai usia. Tujuan penelitian untuk mengetahui status gizi dan grafik pertumbuhan anak usia 0-23 bulan di wilayah kerja Puskesmas Pantoloan. Penelitian deskriptif ini menggunakan data sekunder laporan rutin Puskesmas Pantoloan pada bulan Februari 2020. Sampel adalah seluruh anak baduta usia 0-24 bulan di wilayah kerja Puskesmas Pantoloan sebanyak 319 anak baduta. Status gizi ditentukan dengan indikator berat badan menurut usia $(\mathrm{BB} / \mathrm{U})$ serta tinggi badan menurut usia $(\mathrm{TB} / \mathrm{U})$ yang dibandingkan dengan standar WHO 2005. Hasil penelitian menunjukkan bahwa status gizi menurut indeks Berat badan menurut usia $(\mathrm{BB} / \mathrm{U})$ sebagian besar normal $(84,6 \%)$, Panjang badan menurut usia (PB/U) sebagian besar normal $(83,7 \%)$, dan berat badan menurut panjang bandan $(\mathrm{BB} / \mathrm{PB})$ sebagian besar gizi baik $(87,1 \%)$. Grafik median berat badan dan panjang badan anak baduta menunjukkan kurva pertumbuhan berada di bawah kurva median standar WHO-Antro mulai usia 9 bulan dan tampak jelas ketika anak masuk usia 20-21 bulan. Kesimpulan pada umumnya status gizi normal dan baik, grafik kurva median anak baduta berada di bawah kurva median standar WHO Antro. Disarankan agar pemantauan pertumbuhan dilakukan untuk mengetahui status gizi anak baduta secara teratur.
\end{abstract}

\section{Kata Kunci : Anak Baduta; Status Gizi; Kurva Standar WHO Antro}

\begin{abstract}
Children under two years of age are healthy if they grow and develop adequately. The growth of children under two years is a dynamic process where a growth curve is needed as a comparison tool to determine their age-appropriate growth. The research objective was to determine the nutritional status and growth charts of children aged 0-23 months in the Pantoloan Central of Health Community working area. This descriptive study used secondary data from routine reports of Pantoloan Central of Health Community in February 2020. The sample was all children under 0-24 months in the working area of Puskesmas Pantoloan, as many as 319 children under baduta. Nutritional status was determined by indicators of body weight for age and height for age compared to the 2005 WHO standard. The results showed that nutritional status according to body weight index for age was mostly normal (84.6\%), body length according to age was mostly normal (83.7\%), and body weight according to band length was mostly good nutrition (87.1\%). The graph of the median weight and body length of children under five years of age shows that the growth curve is below the WHO-Antro standard median curve starting at 9 months of age and is evident when the child enters the age of 20-21 months. In conclusion, in general, the nutritional status is normal and good, the graph of the median curve of children under two years is under the WHO Antro standard median curve. It is recommended that growth monitoring be carried out to determine the nutritional status of children under five on a regular basis.
\end{abstract}

Keywords: Children Under Two; Nutritional Status; Curve WHO Antro Standard https://doi.org/10.33860/jik.v14i2.289 


\section{PENDAHULUAN}

Masalah kesehatan anak merupakan masalah utama bidang kesehatan di Indonesia. Derajat kesehatan anak mencerminkan derajat kesehatan bangsa karena anak merupakan generasi penerus bangsa yang memiliki kemampuan yang dapat dikembangkan dalam meneruskan pembangunan bangsa. Usia Baduta adalah usia emas dimana pada usia tersebut, terjadi pertumbuhan fisik dan perkembangan kecerdasan serta emosional anak. Potensi tersebut berkontribusi terhadap pembentukkan sumber daya manusia sebagai generasi penerus bangsa yang berkualitas. Status gizi yang baik mendukung proses pertumbuhan dan perkembangan anak. ${ }^{1}$ Anak-anak dikatakan sehat jika mereka tumbuh dan berkembang secara memadai. Ini ditentukan melalui pengukuran tinggi dan berat badan ideal yang sesuai dengan usia. ${ }^{2}$

Antropometri adalah penggunaan alat ukur tubuh untuk menilai dan mengklasifikasikan status gizi anak. Parameter antropometri yang umum adalah tinggi badan untuk usia yang digunakan untuk menilai stunting. Berat badan menurut usia digunakan untuk mengidentifikasi kekurangan berat badan serta berat badan menurut tinggi badan untuk mendeteksi anakanak yang menderita kekurangan gizi saat ini atau akut dan biasanya disebut dengan istilah wasting. $^{3}$

Menurut World Health Organization, sebanyak 54\% kematian anak disebabkan oleh keadaan gizi yang buruk. ${ }^{4}$ Di Indonesia sendiri mengakibatkan lebih dari 80\% kematian anak yang disebabkan masalah gizi, baik itu karena gizi buruk, gizi kurang dan gizi lebih. Berdasarkan hasil Riset Kesehatan Dasar 2018 di Sulawesi Tengah, prevalensi balita yang mengalami gizi buruk $4,8 \%$, gizi kurang $18,6 \%$, gizi baik $74,7 \%$, dan gizi lebih $1,8 \% .^{5}$ Data Puskesmas Pantoloan tahun 2019 menunjukkan bahwa menurut indikator $\mathrm{BB} / \mathrm{U}$; prevalensi gizi buruk 3,9\%, gizi kurang sebesar $9,7 \%$ dan $4,1 \%$ gizi lebih. Menurut indikator TB/U; Prevalensi sangat pendek $3.1 \%$ sebesar $8,6 \%$ pendek. Menurut indikator $\mathrm{BB} / \mathrm{TB}$ prevalensi sangat kurus $0,8 \%$ dan gemuk 3,2\%. ${ }^{6}$ Data ini menjadi pertimbangan dan perhatian lintas sektor dalam upaya untuk mengatasi masalah gizi di wilayah kerja Puskesmas Pantoloan.

Pertumbuhan anak adalah proses yang dinamis dimana dibutuhkan kurva pertumbuhan sebagai alat pembanding untuk mengetahui pertumbuhannya sesuai usia. Sejak tahun 2006, kurva standar WHO digunakan untuk menilai status gizi. Pemantauan dilakukan dengan melakukan ploting hasil pengukuran ke grafik pertumbuhan. ${ }^{7}$ Pemantauan dan promosi pertumbuhan melalui klinik komunitas telah terbukti meningkatkan status gizi anak anak di bawah usia 2 tahun. ${ }^{8}$

Tujuan penelitian ini untuk mengetahui status gizi dan grafik pertumbuhan anak usia 023 bulan di wilayah kerja Puskesmas Pantoloan.

\section{METODE PENELITIAN}

Penelitian ini merupakan penelitian deskriptif yang menggambarkan status gizi dan grafik median pertumbuhan anak baduta di wilayah kerja Puskesmas Pantoloan. Penelitian dilaksanakan pada bulan Februari tahun 2020. Populasi adalah seluruh anak baduta usia 0-24 bulan dengan sampel seluruh populasi (total sampling) berjumlah 319 anak baduta. Penelitian ini menganalisis data sekunder yang merupakan laporan rutin puskesmas oleh pemegang program gizi. Analisis data penelitian adalah analisis univariat disajikan dalam tabel dan grafik.

\section{HASIL}

\section{Status Gizi anak Baduta}

Tabel 1 menunjukkan bahwa dari 319 baduta berdasarkan indeks antropometri $\mathrm{BB} / \mathrm{U}$ anak yang memiliki status gizi Normal sebanyak 270 orang $(84,6 \%)$, namun terdapat juga baduta yang memiliki status gizi kurang sebanyak 32 orang $(10,0 \%)$, dan sangat kurang sebanyak 8 orang $(2,5 \%)$.

Berdasarkan indeks antropometri $\mathrm{PB} / \mathrm{U}$ anak yang memiliki status gizi Normal sebanyak 267 orang $(83,7 \%)$, status gizi pendek sebanyak 30 orang $(9,4 \%)$ dan sangat pendek sebanyak 18 orang $(5,6 \%)$.

Berdasarkan indeks antropometri $\mathrm{BB} / \mathrm{PB}$ anak yang memiliki status gizi baik sebanyak 278 orang $(87,1 \%)$, baduta yang memiliki status gizi kurang sebanyak 29 orang $(9,1 \%)$ dan gizi buruk sebanyak 12 orang $(3,8 \%)$. 
Tabel 1. Gambaran distribusi status gizi berdasarkan indeks $\mathrm{BB} / \mathrm{U}, \mathrm{PB} / \mathrm{U}$ dan BB/TB di wilayah kerja Puskesmas Pantoloan Tahun 2020

\begin{tabular}{lcc}
\hline \multicolumn{1}{c}{ Status Gizi } & n & \% \\
\hline Indikator BB/U & & \\
Sangat Kurang & 8 & 2,5 \\
Kurang & 32 & 10,0 \\
Normal & 270 & 84,6 \\
Lebih & 9 & 2,8 \\
\hline Indikator TB/U & & \\
Sangat Pendek & 18 & 5,6 \\
Pendek & 30 & 9,4 \\
Normal & 267 & 83,7 \\
Tinggi & 4 & 1,3 \\
\hline Indikator BB/TB & & \\
Gizi Buruk & 12 & 3,8 \\
Gizi Kurang & 29 & 9,1 \\
Gizi Baik & 278 & 87,1 \\
\hline \multicolumn{1}{c}{ Jumlah } & 319 & 100,0 \\
\hline
\end{tabular}

Sumber : Data Sekunder, 2020

\section{Grafik Median Pertumbuhan BB dan PB Anak Baduta}

Grafik 1 menggambarkan bahwa median berat badan menurut usia pada baduta laki-laki usia 0-23 bulan yang berat badannya diatas grafik standar median pertumbuhan ada pada usia 0 bulan dengan selisih berat badan $0,1 \mathrm{~kg}$. Nilai median berat badan yang dibawah grafik standar median pertumbuhan ada pada usia 21 bulan dengan selisih berat badan 2,4 kg kurang dari median standar.

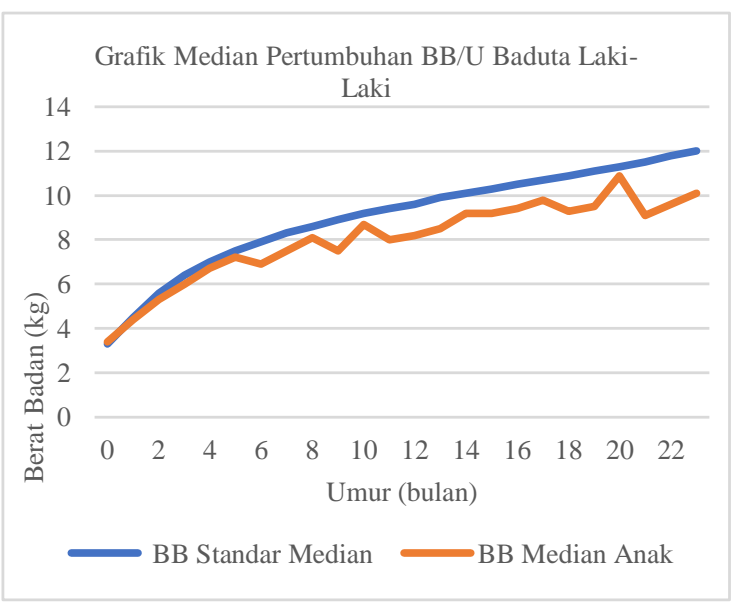

Sumber : Data sekunder, 2020.

Grafik 1. Grafik pertumbuhan anak baduta lakilaki di wilayah kerja Puskesmas Pantoloan di bandingkan grafik median standar WHO antro indeks BB/U

Grafik 2 menggambarkan bahwa median berat badan menurut usia pada baduta perempuan usia 0-23 bulan yang berat badannya diatas grafik standar median pertumbuhan ada pada usia 0 bulan dengan selisih berat badan $0,7 \mathrm{~kg}$. Nilai median berat badan yang dibawah grafik standar median pertumbuhan ada pada usia 21 bulan dengan selisih berat badan 2,2 kg kurang dari median standar.

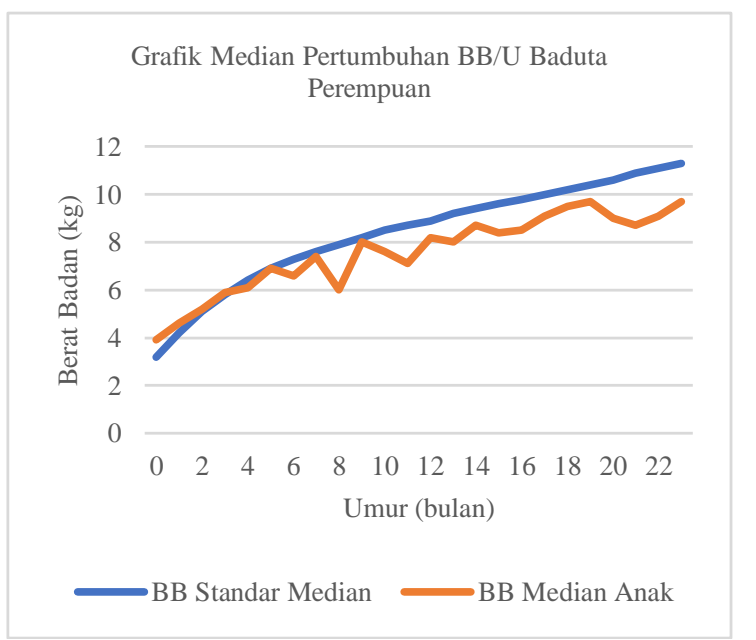

Sumber : Data sekunder, 2020.

Grafik 2. Grafik pertumbuhan anak baduta perempuan di wilayah kerja Puskesmas Pantoloan di bandingkan grafik median standar WHO antro indeks $\mathrm{BB} / \mathrm{U}$.

Grafik 3 menggambarkan bahwa median panjang badan menurut usia pada baduta lakilaki usia 0-23 bulan yang panjang badannya diatas grafik standar median pertumbuhan ada pada usia 11 bulan dengan selisih panjang badan $0,7 \mathrm{~cm}$. Nilai median panjang badan yang dibawah grafik standar median pertumbuhan ada pada usia 21 bulan dengan selisih panjang badan 7,1 cm kurang dari median standar.

Grafik 4 menggambarkan bahwa median panjang badan menurut usia pada baduta Perempuan usia 0-23 bulan yang panjang badannya diatas grafik standar median pertumbuhan ada pada usia 11 bulan dengan selisih panjang badan $5,2 \mathrm{~cm}$. Nilai median panjang badan yang dibawah grafik standar median pertumbuhan ada pada usia 22 bulan dengan selisih panjang badan 7,6 cm kurang dari median standar. 


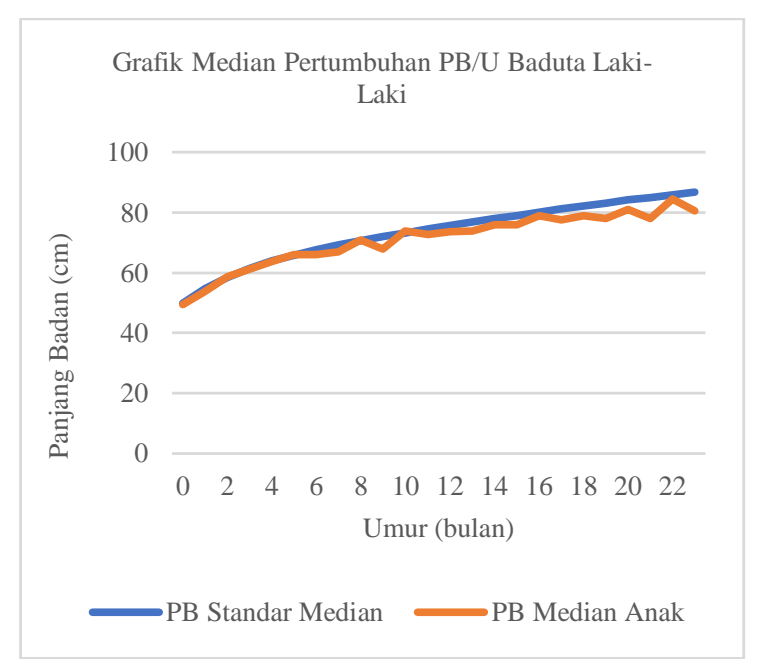

Sumber : Data sekunder, 2020.

Grafik 3. Grafik pertumbuhan anak baduta lakilaki di wilayah kerja Puskesmas Pantoloan di bandingkan grafik median standar WHO antro indeks PB/U

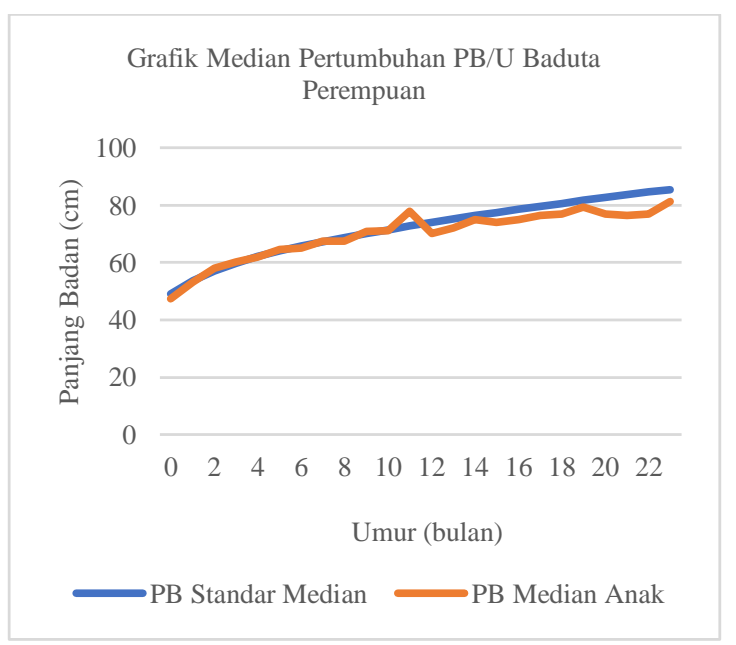

Sumber : Data sekunder, 2020.

Grafik 4. Grafik pertumbuhan anak perempuan di wilayah kerja Puskesmas Pantoloan di bandingkan grafik median standar WHO antro indeks PB/U.

\section{PEMBAHASAN}

\section{Status Gizi anak Baduta}

Pemantauan status gizi merupakan upaya dini dalam mendeteksi masalah gizi yang ada di masyarakat. Kurva WHO merupakan kurva standar yang mengambil populasi dari beberapa negara maju dan berkembang di dunia dan mendeskripsikan bagaimana anak sehat tumbuh dalam kondisi optimal. ${ }^{7}$ Standar tersebut memperlihatkan bagaimana pertumbuhan anak dapat dicapai apabila memenuhi syarat-syarat tertentu. ${ }^{9}$ Hasil penelitian menggambarkan status gizi pada anak baduta di wilayah kerja Puskesmas Pantoloan pada umumnya memiliki normal atau baik. Namun ada juga masalah gizi berat badan kurang, sangat kurang serta lebih. Berat badan merupakan masalah gizi akut yang disebabkan karena asupan makanan dan penyakit infeksi. Usia baduta adalah usia pemberian ASI ekslusif dan MP-ASI mulai anak 6 bulan. Problematika terkait pemberian MP-ASI terkait dengan adekuatnya asupan makanan. Ketidakpatuhan dalam memberi MPASI dalam jumlah yang disarankan dapat berdampak pada pertumbuhan. ${ }^{10}$

Masalah gizi yang masih terdapat pada anak baduta di wilayah kerja Puskesmas Pantoloan juga terkait dengan pendek dan sangat pendek. Pendek atau stunting adalah kondisi kekurangan gizi kronis yang saat ini di Indonesia diperkirkan ada 37,2\% dari anak usia $0-59$ bulan. ${ }^{11}$ Sebaran bayi berat lahir rendah di Indonesia masih tinggi termasuk di Sulawesi Tengah. ${ }^{12}$ Stunting yang tidak dikoreksi dan diatasi pada masa emas periode 1000 hari pertama kelahiran akan berdampak pada proses perkembangan otak dan kemampuan kognitif. Jangka panjang mengurangi kapasitas untuk berpendidikan lebih baik dan hilangnya kesempatan untuk peluang kerja dengan pendapatan lebih baik. Anak stunting yang berhasil mempertahankan hidupnya, pada usia dewasa cenderung akan menjadi gemuk dan berpeluang menderita penyakit tidak menular, seperti hipertensi, diabetes, kanker, dan lainlain. ${ }^{11}$

Faktor risiko stunting pada anak usia 6-23 bulan adalah berat badan lahir rendah, usia anak $12-23$, tinggi badan ibu $<150 \mathrm{~cm}$, pengasuh tidak mencuci tangan menggunakan sabun dan imunisasi dasar yang tidak lengkap. ${ }^{13}$ Program stop buang air besar sembarangan terbukti mencegah stunting. Program ini bertujuan untuk budaya perilaku hidup bersih dan sehat, bertujuan mencegah penyebaran penyakit yang berbasis lingkungan, bertujuan meningkatkan kemampuan masyarakat dalam merubah perilaku tidak melakukan aktivitas buang air besar sembarangan. ${ }^{14}$ Menerapkan intervensi kondisi air, sanitasi dan kebersihan gabungan memiliki manfaat terpenting untuk meningkatkan status gizi. ${ }^{15}$

MP-ASI adalah makanan atau minuman selain ASI yang mengandung nutrien yang diberikan kepada bayi selama periode pemberian makanan peralihan (yaitu pada saat 
makanan /minuman lain diberikan bersama pemberian ASI. $^{7}$ Masalah stunting tertinggi pada kelompok usia 12-23 bulan berarti pencegahan stunting difokuskan pada penguatan program MP-ASI. ${ }^{16}$ Usia lanjut ibu secara positif terkait dengan penurunan praktik menyusui; namun jarak yang baik dan status anak laki-laki melindungi praktik PMBA yang baik. ${ }^{17}$

Pemberian MP-ASI yang baik sangat berpengaruh dalam pencegahan stunting. ${ }^{18}$ Sebuah intervensi Kelas edukasi MP-ASI yang dilakukan di wilayah kerja Puskesmas Pantoloan berpengaruh terhadap nilai z-score $\mathrm{PB} / \mathrm{U}$ sebelum dan sesudah intervensi. ${ }^{19}$ Demikian pula ternyata sosialisasi kader kepada ibu selama dua bulan dapat meningkatkan pertumbuhan balita melalui praktik MP-ASI dan sanitasi penyiapan makanan yang lebih baik. $^{20}$

Efek dari lingkungan terkait dengan status gizi adalah penggunaan pestisida. penggunaan pestisida berdampak negatif terhadap kesehatan dan lingkungan. ${ }^{21}$ Pajanan pestisida dapat menjadi faktor risiko terjadinya gangguan tumbuh kembang pada anak yang tinggal di wilayah pertanian. Tingkat keterpaparan pestisida yang tinggi $(\mathrm{p}=0,029)$ berhubungan dengan stunting. ${ }^{22}$ Penggunaan pestisida berdampak negatif terhadap kesehatan dan lingkungan. ${ }^{21}$

Masalah gizi yang masih dijumpai berikutnya adalah status gizi kurang dan buruk. Penelitian Alinea Dwi Elisanti 2017 menunjukkan bahwa sulawesi tengah masih merupakan daerah yang jumlah sebaran gizi buruknya tinggi. ${ }^{12}$.Pengetahuan ibu yang cukup mengenai jumlah variasi dan pola pemberian MP-ASI yang sesuai usia akan menunjang pertumbuhan dan perkembangan karena terpenuhinya kebutuhan anak. Salah satu pilihan untuk meningkatkan asupan makanan anak baduta dengan memberikan Virgin Coconut Oil. ${ }^{23}$

\section{Grafik Median Pertumbuhan BB dan PB Anak Baduta}

Abnormalitas pada pola pertumbuhan mungkin tidak spesifik, tetapi penting sebagai penanda kemungkinan penyakit kronik serius. Sehingga penting melakukan pengukuran indikator pertumbuhan seperti panjang badan dan berat badan. ${ }^{7}$

Hasil penelitian menunjukkan bahwa baik pada laki dan perempuan nilai median berat badan yang menjauhi grafik median standar pertumbuhan terdapat pada usia 21 bulan. Untuk nilai median panjang badan pada anak baduta laki-laki dan perempuan yang berada di bawah terjadi pada usia 21-22 bulan. Usia ini adalah fase terakhir di usia pemberian MP-ASI yang sudah diperkenalkan MP-ASI.

Pola pertumbuhan normal memiliki masa percepatan spurt dan masa perlambatan plateau sehingga pergeseran pada persentil dapat terjadi. Namun, pergeseran persentil yang ekstrim perlu dimonitor, begitu juga selisih yang besar pada panjang atau tinggi badan, berat badan, dan lingkar kepala. Ketika asupan gizi tidak memadai, indikator yang pertama kali menurun adalah berat badan, disusul dengan tinggi badan, dan terakhir adalah lingkar kepala. $^{24}$

Pola normal mengikuti median standar kurva perumbuhan dalam penelitian ini ada pada usia pemberian ASI ekslusif yaitu 0-6 bulan, kurva pertumbuhan anak baduta yang ada di wilayah kerja Puskesmas Pantoloan mulai menunjukkan menjauhi kurva median standar kearah bawah untuk berat badan diawali terjadi di usia 5 bulan sedangkan untuk panjang badan di usia 9 bulan baik pada anak baduta laki-laki dan perempuan.

Analisis pola pertumbuhan awal pada anak-anak dari 54 negara miskin sumber daya di Afrika dan Asia Tenggara menunjukkan penurunan yang cepat pada skor z tinggi badan untuk usia selama 2 tahun pertama kehidupan dan tidak ada pemulihan hingga usia $\geq 5$ tahun. Temuan ini telah memusatkan perhatian pada periode -9 hingga 24 bulan sebagai jendela peluang untuk intervensi melawan stunting dan telah mendapatkan dukungan politik yang cukup besar untuk investasi yang ditargetkan pada 1000 hari pertama. ${ }^{25}$

Status gizi dan grafik pertumbuhan yang diperoleh pada penelitian ini dilakukan pada bulan Februari yang merupakan bulan pemberian Vitamin A. Vitamin A diberikan pada musim pancaroba, sebagai upaya untuk meningkatkan kekebalan tubuh anak terhadap penyakit yang biasanya muncul pada musim pancaroba. Vitamin A telah terbukti mencegah kesakitan dan stunting pada anak baduta. ${ }^{26}$ Bahkan lebih jauh lagi sebenarnya pemerintah Indonesia memprogramkan pemberian kapsul Vitamin A 200.000 IU untuk ibu nifas. sebagai upaya mencegah kekurangan Vitamin A pada ASI ibu yang menyusui. ${ }^{27}$ 
Saluran untuk penyebarluasan informasi tentang 1000 hari pertama kehidupan dapat melalui pemanfaatan flipchart ibu hamil, ibu menyusui dan anak berusia 6-23 bulan. Flipchart dan spanduk merupakan media komunikasi perubahan perilaku yang dapat meningkatkan efektivitas dari upaya program spesifik 1000 hari pertama kehidupan. ${ }^{28}$ Kampanye advokasi kesadaran akan pentingnya ASI eksklusif serta komitmen untuk menghindari pemberian susu botol. Jika penggunaan susu botol tidak dapat dihindari, maka diperlukan pendidikan tentang cara pemberian susu botol yang benar, seperti teknik dan kebersihan untuk mengurangi dampak buruk pemberian susu botol. ${ }^{29}$

\section{KESIMPULAN DAN SARAN}

Status gizi balita di wilayah kerja Puskesmas Pantoloan menurut indeks Berat badan menurut usia $(\mathrm{BB} / \mathrm{U})$ sebagian besar normal, Panjang badan menurut usia $(\mathrm{PB} / \mathrm{U})$ sebagian besar normal, dan berat badan menurut panjang bandan $(\mathrm{BB} / \mathrm{PB})$ sebagian besar gizi baik. Masalah gizi yang masih di temukan adalah berat badan lebih, berat badan kurang dan sangat kurang, pendek dan sangat pendek serta gizi kurang dan buruk. Grafik median berat badan dan panjang badan anak baduta menunjukkan kurva pertumbuhan yang cenderung berada di bawah kurva median standar WHO antro mulai usia 9 bulan dan tampak jelas ketika anak masuk usia 20-21 bulan. Rekomendasi dari penelitian ini adalah perlunya perhatian yang lebih dalam penanganan masalah gizi pada usia baduta dalam mencegah kejadian dan dampak stunting pada anak dengan pendampingan pada ibu terhadap pemberian ASI ekslusif dan MP-ASI.

\section{UCAPAN TERIMA KASIH}

Terimakasih diucapkan kepada Kepala Puskesmas Pantoloan dan petugas gizi yang telah membantu dalam pelaksanan penelitian ini. Kepada Nasrul, SKM, M.Kes atas bimbingan teknis penulisan artikel dan referensi yang terkait dengan topik penelitian ini.

\section{DAFTAR PUSTAKA}

1. Kementerian Kesehatan RI. Buku saku pemantauan status gizi. Buku saku pemantauan status gizi tahun 2017. 2018;7-11.

2. Taqwin T, Ramadhan K, Hadriani H, Nasrul N,
Hafid F, Efendi F. Prevalence of Stunting among 10-Year Old Children in Indonesia. J Glob Pharma Technol [Internet]. 2020;12(2 (Suppl.)):|768-773. Tersedia pada: http://www.jgpt.co.in/index.php/jgpt/article/vi ew/3375/2658

3. Akanbiemu FA. Household food insecurity and child nutritional status: Pattern, causes, and relationship. Handbook of Famine, Starvation, and Nutrient Deprivation: From Biology to Policy. 2019. hal. 235-56.

4. Faridah U, Charmenita N, Program. Motivasi Kader dan Kelengkapan Pengisian Kartu Menuju Sehat Balita di Kabupaten Kudus. Indones J Kebidanan. 2017;8(2):39-43.

5. Kementerian Kesehatan RI. Laporan Riskesdas 2018. Vol. 53, Kementerian Kesehatan RI. 2018. 181-222 hal.

6. Dinkes. Diseminasi Laporan Pemantauan Status Gizi (PSG) Propinsi Sulawesi Tengah. In: Diseminasi Laporan Pemantauan Status Gizi (PSG) Propinsi Sulawesi Tengah. 2015.

7. Pulungan AB. Auxology, Kurva Pertumbuhan, Antropometri, dan Pemantauan Pertumbuhan. Sari Pediatr. 2020;

8. Hossain M, Ferdous T-E-, Islam Z, Billah SM, Bulbul MMI, Rahman MM, et al. Protocol for a quasiexperimental study testing the effectiveness of strengthening growth monitoring and promotion in community clinics for improving the nutritional status of under-two children in rural Bangladesh. BMJ Open. Oktober 2019;9(10):e032458.

9. RI K. Peraturan Menteri Kesehatan Republik Indonesia Nomor 2 Tahun 2020 tentang Standar Antropometri Anak. Nomor 2 Tahun 2020 Jakarta, Indonesia: Kemenkes RI; 2020 hal. 1-78.

10. Flax VL, Phuka J, Cheung YB, Ashorn U, Maleta K AP. Feeding patterns and behaviors during home supplementation of underweight Malawian children with lipid-based nutrient supplements or corn-soy blend. Appetite. 2010;54(3):504-11.

11. Kemenkes RI. Buletin Stunting. Kementeri Kesehat RI. 2018;301(5):1163-78.

12. Elisanti AD. Pemetaan Status Gizi Balita di Indonesia. Indones J Heal Sci. 2017;1(1):3742.

13. Nasrul, Hafid F, Razak Thaha A, Suriah. Faktor Risiko Stunting Usia 6-23 Bulan di Kecamatan Bontoramba Kabupaten Jeneponto. Media Kesehat Masy Indones. 2015;11(3):139-46.

14. Hafid F, Djabu U, Udin, Nasrul. Efek Program SBABS Terhadap Pencegahan Stunting Anak Baduta di Kabupaten Banggai dan Sigi. Indones J Hum Nutr. 2017;4(2):79-87.

15. Revuelta Iniesta R, Paciarotti I, Davidson I, McKenzie JM, Brougham MFH, Wilson DC. 
Nutritional status of children and adolescents with cancer in Scotland: A prospective cohort study. Clin Nutr ESPEN. Agustus 2019;32:96106.

16. Nasrul, Maudu R, Hafid F. Trend and Prevalence of Stunting in Children Under Two Years From 2007- 2016 In Central Sulawesi. Prev J Kesehat Masy. 2017;8(2):73-8.

17. Kar S, Esther A. Complacent child feeding practices versus infant feeding practices affecting the nutritional status of under two children situational analysis. Indian $\mathrm{J}$ Community Heal. 2020;32(1):43-50.

18. Stewart CP, Iannotti L, Dewey KG, ... Contextualising complementary feeding in a broader framework for stunting prevention. Matern child .... 2013;

19. Kusumawati DE, Ansar A, Bahja B, Hafid F. Workshop Praktek Pemberian Makanan Pendamping Asi (MP-ASI) bagi Baduta pada Kader Posyandu. Poltekita J Pengabdi Masy. 2020;1(1).

20. Kartasurya MI, Pangestuti DR, Kusumawati A, Dina RA, Pertiwi J, Izwardy D, et al. Cadres Outreach Program to Mothers Improve Nutritional Status of Under Two Year Old Children. Indian J Public Heal Res Dev. 2019;10(3):917.

21. Amsal, Hafid F, Ramlan, Masrianih. Pesticide Poisoning in Farmers and Its Risk Factors in Tolai Village, Parigi Moutong Regency, Indonesia. Indian J Public Heal Res Dev. 2019;10(8):1181.

22. Kartin A, Subagio HW, Hadisaputro S, Kartasurya MI, Suhartono S, Budiyono B. Pesticide Exposure and Stunting among Children in Agricultural Areas. Int J Occup
Environ Med. Januari 2019;10(1):17-29.

23. Sari D, Indriasari R, Zulkifli A. The Effect of Giving VCO (Virgin Coconut Oil) on the Nutritional Status of Under Nutrition Children Aged 24-58 Months Old in Bontoramba Subdistrict Jeneponto Regency. Indian J Public Heal Res Dev. 2019;10(4):990.

24. DA. L. Growth and development. 8 ed. Essentials of Pediatrics. Philadelphia: Elsevier; 2015. 151-5 hal.

25. Prentice AM, Ward KA, Goldberg GR, Jarjou LM, Moore SE, Fulford AJ, et al. Critical windows for nutritional interventions against stunting. Am J Clin Nutr. 2013;97(5):911-8.

26. Nasrul N, Taqwin T, Hafid F. The Prevention Against Morbidity and Stunting Through Vitamin A Supplementation In Sigi and Touna Districts. In: Pontianak International Health Conference (PIHC). ISBN 978-602-51424-06; 2017. hal. 317-25.

27. Taqwin, Lisnawati, Sumiaty, Hafid F. Implementasi Pemberian Vitamin A bagi Ibu Nifas di Kota Palu dan Kabupaten Sigi. Poltekita J Ilmu Kesehat. 2020;14(1):11-7.

28. Nasrul, Zainul, Hafid F, Taqwin. Manfaat Media Flipchart dan Spanduk dalam Perilaku Kesehatan 1000 HPK di Sulawesi Tengah. Media Kesehat Masy Indones. 2018;14(1):5260.

29. Nasrul N, Hafid F, Ramadhan K, Suza DE, Efendi F. Factors Associated with Bottle Feeding in Children Aged 0-23 Months in Indonesia. Child Youth Serv Rev [Internet]. September 2020;116(September):105251. Tersedia pada: https://linkinghub.elsevier.com/retrieve/pii/S0 190740920305983 